\title{
Transgenic Tall Fescue and Maize with Resistance to ALS-Inhibiting Herbicides
}

\author{
Hiroko Sato ${ }^{1}$, Tadashi Takamizoㅁ, Junko Horita ${ }^{2}$, \\ Kiyoshi Kawai2, Koichiro Kaku² and Tsutomu Shimizu² \\ ${ }^{1}$ National Institute of Livestock and Grassland Science \\ ${ }^{2}$ Life Science Research Institute, Kumiai Chemical Industry Co. \\ Japan
}

\section{Introduction}

Transgenic crops such as maize (Zea mays L.), soybeans (Glycine max L. Merr.), canola (Brassica napus L.) and cotton (Gossypium hirsutum L.) have been widely used in the field. In 2009, transgenic crops were cultivated in approximately 134 million hectares in 25 countries, mainly USA, Brazil, Argentina, India, Canada and China (http://www.isaaa.org). The adoption of transgenic crops has steadily increased since 1996 because of their many benefits for farmers. Herbicide resistance is one of the most important agronomic traits conferred onto transgenic crops. Herbicide-resistant crops comprise 62 percent of all transgenic crops (http://www.isaaa.org), and are produced by the introduction of herbicide-resistant genes using genetic transformation. Herbicide resistance can be used as an efficient tool to allow easier weed management. It facilitates control of weed species and contributes to reducing costs, labor, and the waste of chemical spray. Herbicide resistance can also facilitate the selection of transgenic cells from non-transgenic cells as a selectable marker in genetic transformation.

Acetolactate synthase (ALS)-inhibiting herbicides are widely used around the world. ALSinhibiting herbicide-resistant weeds were first found in kochia (Kochia scoparia L. Shrad) (Primiani et al., 1990) and prickly lettuce (Lactuca serriola L.) (Mallory-Smith et al., 1990). Subsequently, plants and cultured cells resistant to ALS-inhibiting herbicides have been generated using both conventional mutation breeding and somatic cell selection. Since then, the ALS genes have been cloned and characterized. In most cases, resistance to ALSinhibiting herbicides has been found to be conferred by single or double amino-acid mutations at a particular position in ALS. Mutated ALS genes can be used not only for the generation of herbicide-resistant crops, but also as selectable markers.

We are now producing transgenic tall fescue (Festuca arundinacea Schreb.) and maize that are resistant to ALS-inhibiting herbicides using novel mutated ALS genes. This chapter focuses on mutated ALS genes and their application to the production of herbicide-resistant crops and selection of transgenic cells as selectable markers.

\subsection{ALS-inhibiting herbicides}

ALS (EC 2.2.1.6; also referred to as acetohydroxyacid synthase, AHAS) is the first common enzyme in the biosynthetic pathway leading to the branched-chain amino acids, isoleucine, leucine and valine (Fig. 1). It is a highly conserved enzyme in higher plants. ALS moves to 
the chloroplast with the use of a transit peptide. Although ALS functions in plastids, ALS is a dominant and nuclear gene, and thus follows normal Mendelian inheritance.

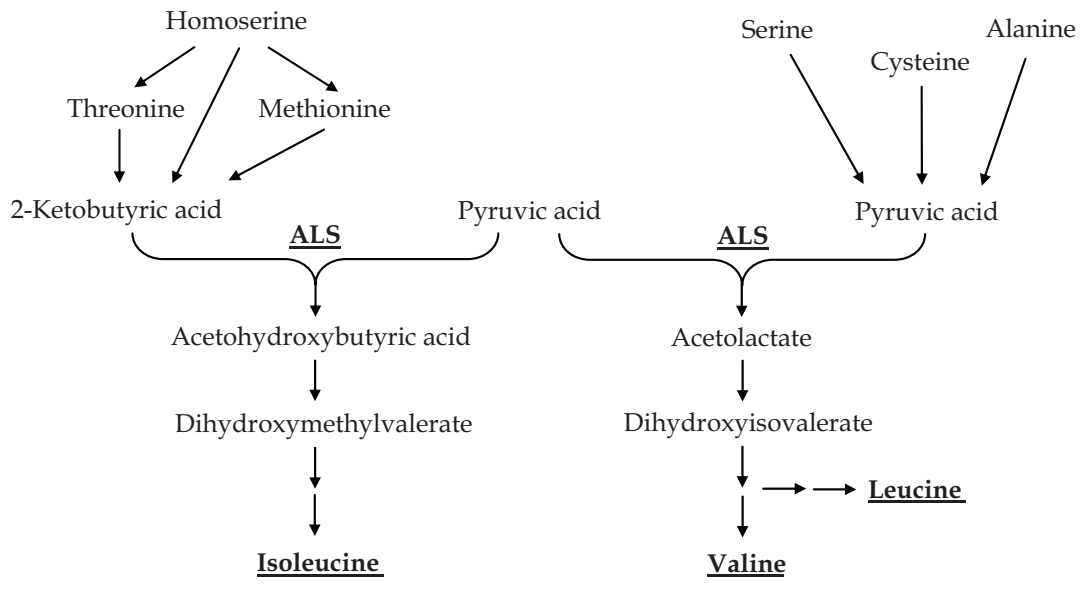

Fig. 1. The biosynthesis pathway of branched-chain amino acids. ALS-inhibiting herbicides inhibit ALS.

ALS is the target enzyme of at least five structurally distinct classes of herbicides; pyrimidinylcarboxylates (PCs), sulfonylureas (SUs), imidazolinones (IMs), triazolopyrimidine sulfonamides and sulfonylaminocarbonyltriazolinones (Shimizu et al., 2002). These herbicides all bind to ALS, but not all at the same attachment points. ALSinhibiting herbicides are widely used around the world and account for about $17.5 \%$ of the total global herbicide market (Green, 2007). There are more than 50 commercial herbicides from these five classes of herbicides used for selective weed control. Some representative ALS-inhibiting herbicides are shown in Fig. 2. These herbicides control an immense variety of grass and broadleaf weeds.

When we spray plants with these herbicides, plants cannot biosynthesize essential amino acids due to the inhibition of ALS and they come to die. ALS-inhibiting herbicides are used for controlling weed species at relatively low application rates and have both foliar and soil residual activity. Furthermore, ALS does not exist in mammals; thus, ALS-inhibiting herbicides are thought to be less toxic to mammals.

\subsection{Mutated ALS genes confer resistance to ALS-inhibiting herbicides}

Resistance to ALS-inhibiting herbicides in plants has in most cases been conferred by either single or double-mutant amino-acid substitutions at a particular position in ALS. Different types of mutation have been found to confer resistance to different classes of herbicide (Table 1).

The most commonly encountered mutations involve the residues of alanine at position 96 (A96), proline at position 171 (P171), tryptophane at position 548 (W548) and serine at position 627 (S627); Mutations were described using the rice numbering system. The mutation of the residue of tryptophane 548 substituted with leucine (W548L) was first isolated together with the mutation of the residue of proline at position 171 substituted with alanine (P171A) in tobacco (Nicotiana tabacum L.) by selection using SU (Lee et al., 1988). Subsequently, the mutation has been found in maize (Bernasconi et al., 1995) and canola 


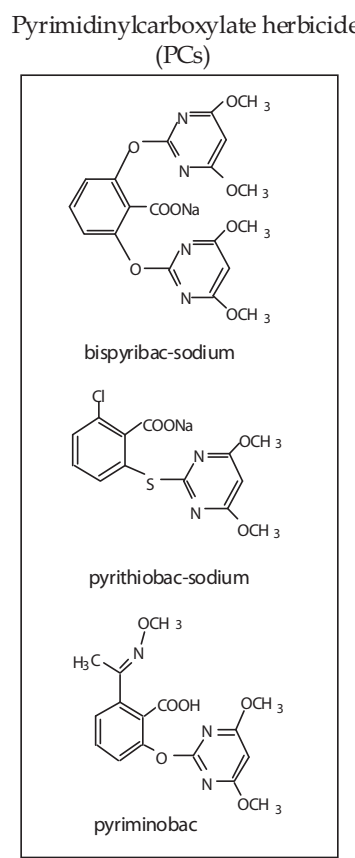

Sulfonylurea herbicides

(SUs)

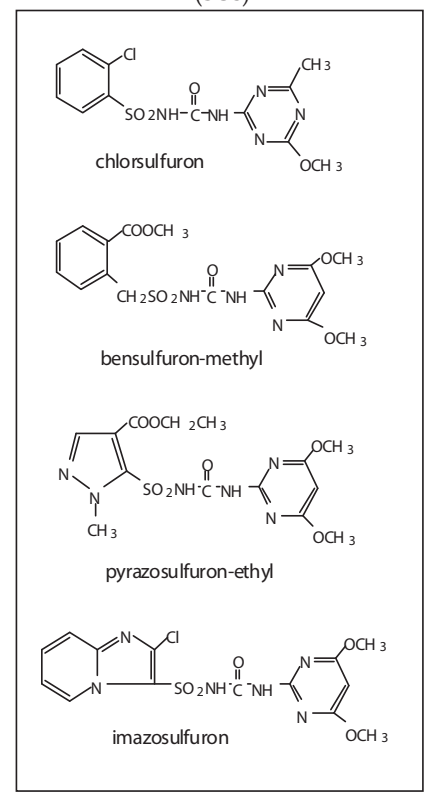

Imidazolinone herbicides (IMs)

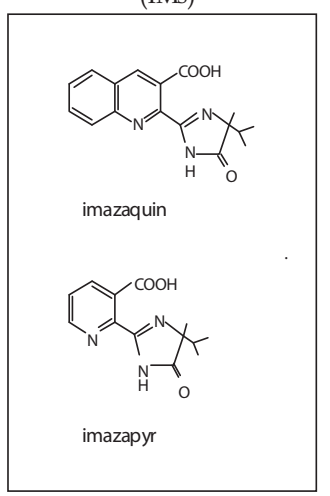

Fig. 2. ALS-inhibiting herbicides.

(Hattori et al., 1995). This mutation confers resistance to different classes of ALS-inhibiting herbicides, SUs and IMs. At this position, other amino-acid substitutions, W548C and W548S, have been identified in cotton (Rajasekaran et al., 1996).

A mutation of S627 was first found in IM-resistant Arabidopsis thaliana (Haughn \& Somerville, 1990). In contrast to W548L, this mutation of S627N confers resistance to IM, but not to SU. The mutation at this position leading to S627A, S627N, S627T and S627F has been analyzed in Arabidopsis by site-directed mutagenesis (Lee et al. 1999).

Double mutations such as P171A/W548L in tobacco (Lee et al., 1988), P171S/S627N in Arabidopsis (Hattori et al., 1992) and A96T/P171S in sugar beets (Beta vulgaris L.) (Wright et al., 1998) have been reported.

Some amino acid substitutions conferring herbicide resistance are well conserved in plant ALS (Tan et al., 2005). We can artificially develop an herbicide-resistant ALS gene using this information even if mutations that confer herbicide resistance have not been characterized in the target plant. When we produce transgenic plants, it is desirable to use transgenes derived from host plant DNA as much as possible. This will be applicable to the production of cisgenic plants with public acceptance (Schouten et al., 2006).

\subsection{A two-point mutated rice (Oryza sativa L.) ALS gene conferred resistance to a PC herbicide}

Double mutations have been found in the rice ALS gene through cell culture using bispyribac-sodium (BS), a PC herbicide (Kawai et al., 2007b). Before isolation of the mutated ALS gene, no paper had reported a mutated ALS gene as conferring resistance to PC herbicides. The mutations were selected from BS-resistant calli produced spontaneously by somaclonal variation during tissue culture. 


\begin{tabular}{|c|c|c|c|}
\hline Plant species & Mutationa) & Methodb) & Selection agent \\
\hline Zea mays & A96T & CMB & Imidazolinone \\
\hline Beta vulgaris & A96T & SCS & Imidazolinone \\
\hline Arabidopsis thaliana & A96V & SDM & \\
\hline Arabidopsis thaliana & M98E & SDM & \\
\hline Arabidopsis thaliana & M98I & SDM & \\
\hline Arabidopsis thaliana & M98H & SDM & \\
\hline Arabidopsis thaliana & P171S & $\mathrm{CMB}$ & Sulfonylurea \\
\hline Nicotiana tabacum & P171Q & SCS & Sulfonylurea \\
\hline Nicotiana tabacum & P171A & SCS & Sulfonylurea \\
\hline Nicotiana tabacum & P171S & SCS & Sulfonylurea \\
\hline Beta vulgaris & P171S & SCS & Sulfonylurea \\
\hline Brassica napus & P171S & SDM & \\
\hline Arabidopsis thaliana & P171 deletion & SDM & \\
\hline Arabidopsis thaliana & R173A & SDM & \\
\hline Arabidopsis thaliana & R173E & SDM & \\
\hline Arabidopsis thaliana & F180R & SDM & \\
\hline Zea mays & W548L & $\mathrm{CMB}$ & Imidazolinone \\
\hline Nicotiana tabacum & W548L & SCS & Sulfonylurea \\
\hline Brassica napus & W548L & SCS & Sulfonylurea \\
\hline Oryza sativa & W548L & SCS & Pyrimidinylcarboxylate \\
\hline Gossypium hirsutum & W548S & SCS & Sulfonylurea \\
\hline Gossypium hirsutum & W548C & SCS & Sulfonylurea \\
\hline Arabidopsis thaliana & W548L & SDM & \\
\hline Nicotiana tabacum & W548F & SDM & \\
\hline Arabidopsis thaliana & W548S & SDM & \\
\hline Arabidopsis thaliana & W548 deletion & SDM & \\
\hline Zea mays & S627D & CMB & Imidazolinone \\
\hline Arabidopsis thaliana & S627N & SCS/SDM & Imidazolinone \\
\hline Zea mays & S627N & SCS & Imidazolinone \\
\hline Oryza sativa & S627I & SCS & Pyrimidinylcarboxylate \\
\hline Arabidopsis thaliana & S627T & SDM & \\
\hline Arabidopsis thaliana & S627F & SDM & \\
\hline Arabidopsis thaliana & S627 deletion & SDM & \\
\hline Oryza sativa & G95A & SCS & Pyrimidinylcarboxylate \\
\hline
\end{tabular}

a) Mutations were described using the rice numbering system. Amino acids are described by one letters. $\mathrm{A}=$ alanine; $\mathrm{C}=$ cysteine; $\mathrm{D}=$ aspartic acid; $\mathrm{E}=$ glutamic acid; $\mathrm{F}=$ phenylalanine; $\mathrm{G}=$ glycine; $\mathrm{H}=$ histidine; $\mathrm{I}=$ isoleucine; $\mathrm{L}=$ leucine; $\mathrm{M}=$ methionine; $\mathrm{N}=$ asparagine; $\mathrm{P}=$ proline; $\mathrm{Q}=$ glutamine; $\mathrm{R}=$ arginine; $\mathrm{S}=$ serine; $\mathrm{T}=$ threonine; $\mathrm{V}=$ =valine; $\mathrm{W}=$ tryptophane. b) Mutated ALSs were obtained through conventional mutation breeding (CMB), somatic cell selection (SCS) or site-directed mutagenesis (SDM).

Table 1. Mutations in ALS conferring resistance to ALS-inhibiting herbicides (Adapted from Kawai et al., 2007b). 
The mutations involved W548L and the residue of serine at position 627 being substituted with isoleucine (S627I). These mutations are a new combination of spontaneous mutations with a novel substitution at the S627 position. The resistance to BS was extremely high as compared with those to SUs and IMs. The single mutations of W548L and S627I in ALS conferred resistance to BS, and the degree of resistance was higher in W548L than in S627I (Fig. 3A). The resistance to BS among these single-mutated ALSs was shown to be lower than that of the double-mutated ALS (Fig. 3A). The W548L mutation also conferred resistance to chlorsulfuron (CS), a SU herbicide, while the S627I mutation conferred no obvious resistance (Fig. 3B). A comparison of the degree of resistance to CS between the W548L single mutation and the W548L/S627I double mutation revealed that they shared the same degree of resistance to CS (Fig. 3B.) Therefore, when it was introduced into an ALS gene carrying the W548L mutation, the S627I mutation was shown to drastically enhance BS resistance in particular.

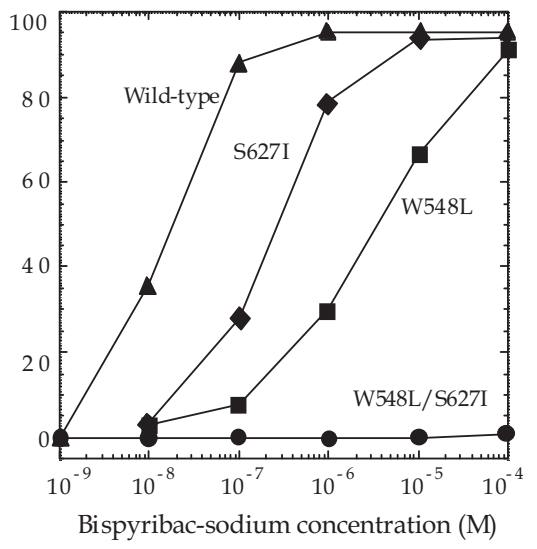

A

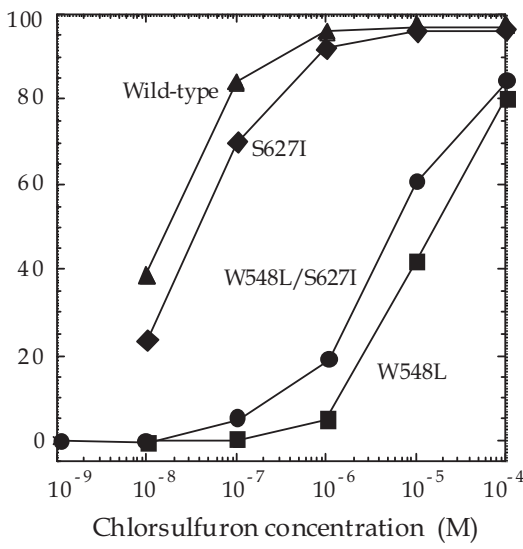

B

Fig. 3. Sensitivity of recombinant rice ALSs to bispyribac-sodium (A) and chlorsulfuron (B) (Adapted from Kawai et al., 2007b).

A two-point mutated rice ALS gene, OsALS (dm), was created when two-point mutations, W548L and S627I, in the OsALS gene were introduced by site-directed mutagenesis. The OsALS $(\mathrm{dm})$ gene was introduced into rice by Agrobacterium-mediated transformation (Kawai et al., 2007a). After spraying over the leaves and stems of transgenic rice carrying the OsALS (dm) gene, they grew normally, indicating that the OsALS (dm) gene acted functionally in rice plants. Expression levels of both endogenous and mutated ALS genes of transgenic rice plants were correlated with the resistance of transgenic plants to BS. The BS resistance of transgenic plants was stably inherited to the progeny in a Mendelian manner.

\section{Production of transgenic herbicide-resistant tall fescue for turf}

Tall fescue is a major cool-season perennial grass species. It is an outcrossing, openpollinated, and highly self-imcompatible grass species; therefore, generally genetic improvement takes a long time. Genetic transformation can help to overcome the problem and facilitate grass improvement. Because of its agronomic importance, many Agrobacterium-mediated transformation systems have been developed in tall fescue (Bettany et al., 2003; Dong et al., 2005; Wang et al., 2005; Gao et al., 2008). Tall fescue is widely used 
not only as forage in pastures, but also as turf for lawns, golf courses, athletic fields, roadsides, and other places. Applying herbicide to tall fescue in pasture or meadow is unrealistic because of the cost and safety, but its application in turf is promising. In turfgrass, weed management is very important, and herbicide resistance can be used as an efficient tool to allow easier maintenance.

We introduced the OsALS $(\mathrm{dm})$ gene into turf-type tall fescue to confer herbicide resistance using Agrobacterium-mediated transformation (Sato et al., 2009). Agrobacterium tumefaciens strain EHA105 carries the binary vector pMLH7133-OsALS (dm) consisting of the OsALS $(\mathrm{dm})$ gene and hygromycin phosphotransferase gene (hpt) under the control of the enhanced cauliflower mosaic virus (CaMV) 35 S promoter (Kawai et al., 2007a). Embryogenic calli were induced from shoot tips of the turf-type tall fescue cultivar Tomahawk germinated in vitro. Infected calli were selected by incubation with hygromycin. Hygromycin-resistant calli were regenerated, transferred to soil and grown in a greenhouse.

Introduction of the OsALS $(\mathrm{dm})$ and hpt genes was confirmed by PCR analysis. The PCR products amplified by the OsALS $(\mathrm{dm})$ primers from both regenerated and wild-type plants were equivalent in size to a fragment amplified from the binary vector pMLH7133-OsALS (dm). Because the ALS genes are well conserved in plants, the PCR from the wild-type plant would be amplified from the endogenous tall fescue ALS gene (FaALS). In the OsALS (dm) gene, two new MfeI sites are produced at the mutation sites (Osakabe et al., 2005), and thus the primers were designed to cover one MfeI site to distinguish the OsALS (dm) from the FaALS gene. After the PCR products were digested with $M f e I$, the regenerated plants and pMLH7133-OsALS (dm) yielded two fragments, whereas the wild-type plant yielded a single fragment. The copy number of integrated genes was estimated by Southern blot analysis and ranged from one to five.

Transgenic plants were sprayed on the leaves with a commercial ALS-inhibiting herbicide containing BS. Wild-type plants were confirmed to die completely after herbicide treatment (Fig. 4). On the other hand, transgenic plants were unaffected by the treatment and showed resistance to the herbicide (Fig. 4).

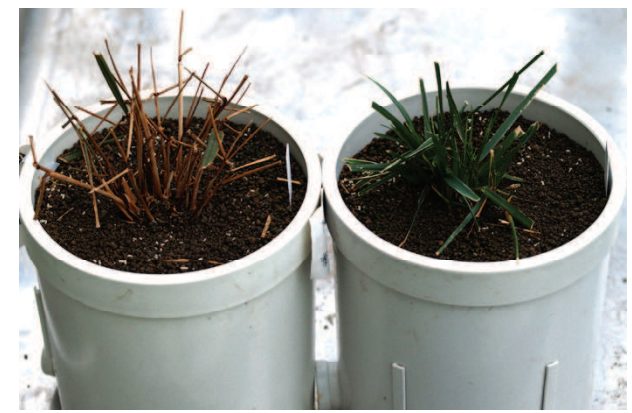

Fig. 4. Herbicide application to wild-type (left) and transgenic plants (right). The picture was taken 45 days after herbicide treatment.

ALS activity in the transgenic plants under the herbicide treatment was analyzed by colorimetric enzymatic assay (Osakabe et al., 2005) with some minor modifications. This assay is able to estimate ALS activity in plant tissues with or without herbicide treatment based on a comparison of acetoin accumulation (Gerwick et al., 1993). Red or pink coloration indicates a high accumulation of acetoin produced by the ALS activity, and yellow or brown 
indicates a low accumulation of acetoin. When the leaf tissues were incubated without BS, both wild-type and transgenic plants produced pink coloration (Fig. 5A). When incubated with BS, only transgenic plants produced pink coloration while the wild-type plants produced a brown color (Fig. 5A).

When ALS activity with BS was measured by a spectrophotometer, the ALS activity in transgenic plants was almost equivalent to that in wild-type plants without BS and showed higher activity than in wild-type plants (Fig. 5B). In the assay without BS, the ALS activity tended to be higher in transgenic plants than in wild-type plants because OsALS (dm) protein would be produced in addition to the endogenous FaALS protein. The transgenic plants showed lower ALS activity with BS than without BS, probably because the FaALS protein was inhibited by BS treatment. These results indicated that the transgenic plants actively produced OsALS $(\mathrm{dm})$ protein under herbicide treatment.

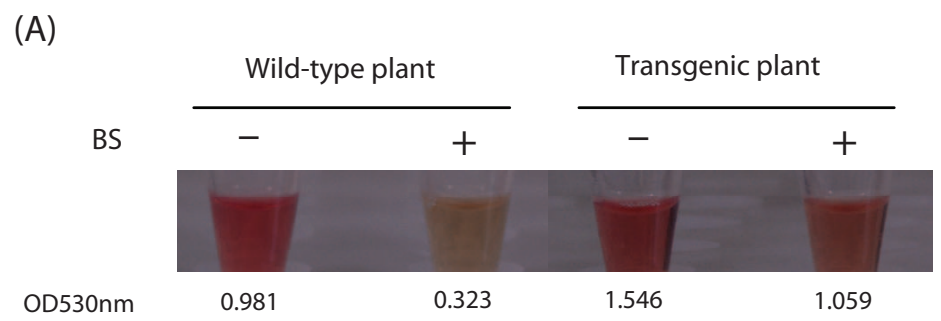

(B)

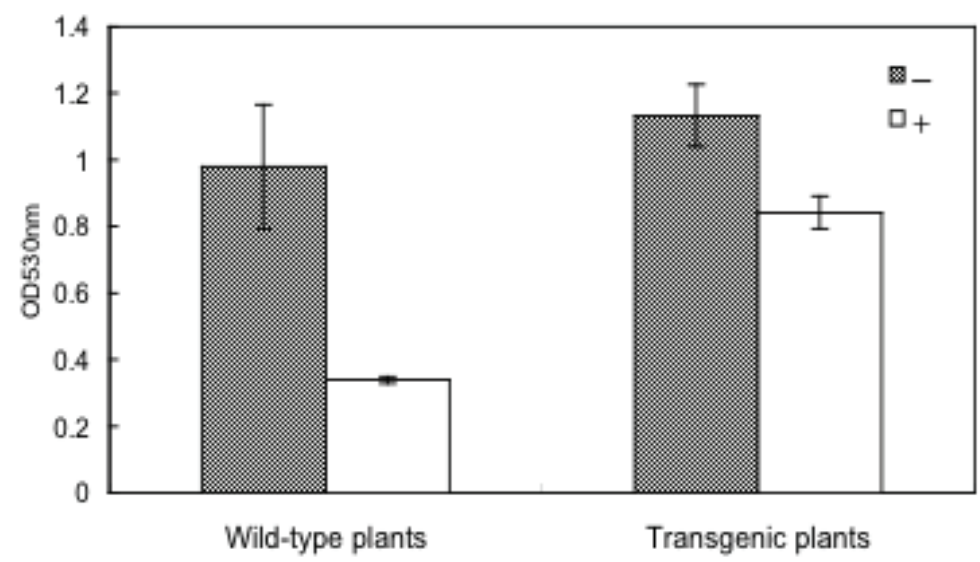

Fig. 5. Colorimetric enzymatic assay in leaves of wild-type and transgenic plants resistant to herbicide. The leaf tissues were incubated with (+) or without (-) BS. (A) Comparison of acetoin accumulation. (B) Measurement of ALS activity. Error bars represent the SE for wildtype plants $(n=3)$ and transgenic plants $(n=9)$ (Adapted from Sato et al., 2009).

Although the transgenic plants were confirmed to show herbicide resistance in the greenhouse, they should be further examined to ensure that herbicide resistance is stable under field conditions. However, since tall fescue is an open-pollinated and anemophilous grass, it is possible that transgenes could be dispersed into the environment through pollen. 
Lee (1996) discussed two environmental risks associated with transgenic turfgrass. The first risk is the possibility that transgenes will be spread by crossing transgenic plants with weed species. The second is the chance that transgenic plants will themselves become weeds. Tall fescue produces large amounts of pollen-containing allergenic proteins that cause hay fever in susceptible people. In tall fescue, plants with cytoplasmic male sterility have been developed to limit grass pollen allergy (Fujimori, 2002). To minimize the risk of dispersal of transgenic pollen in the field, we are crossing such cytoplasmic male-sterile plants with our transgenic plants.

\section{Production of transgenic maize using a mutated $A L S$ gene derived from host maize DNA}

Four commercial hybrid maize varieties resistant to ALS-inhibiting herbicides (IM and SU) were developed by a somatic cell selection method with a B73 $\times$ A188 callus tissue culture (Tan et al., 2005) with a single mutation (W574L, S653N and T155A). A double mutation (P197A and W574L) that showed enhanced resistance to ALS-inhibiting herbicides was later discovered and called a highly herbicide-resistant ALS (HRA).

The first transgenic maize resistant to ALS-inhibiting herbicides was produced by Pioneer Hi-Bred with this HRA gene. The transgenic maize not only has resistance to ALS-inhibiting herbicides but also to glyphosate introduced by Bacillus-derived 5-enolpyruvylskimate-3phosphate synthase (EPSPS) in the same vector. As for regulatory elements, an ALS genederived promoter with three copies of a CaMV 35 S enhancer and potato (Solanum tuberosum L.) protease inhibitor II-derived terminator was used. Nicosulfuron and rimsulfuron were used to check the resistance to ALS-inhibiting herbicides of the transgenic maize. This event has already been named DP-098140, OECD UI: DP-098140-6 (https://bch.cbd.int/ database/record-v4.shtml?documentid $=48466$ ) and has been approved in several countries.

It is important to pay attention to the production of consumer-acceptability of transgenic crops in certain countries, including Japan. In order to produce transgenic maize plants carrying only host-derived genes which are more acceptable, we isolated a maize ALS gene inducing both a promoter and terminator region from a Japanese inbred line, and then introduced the same mutations as in rice but at different positions (W542L and S621I) to confer ALS-inhibiting herbicide resistance. Its resistance to BS was also confirmed by analyzing the enzymatic activities. This mutated ALS gene was again introduced to maize by an improved Agrobacterium-mediated transformation method (Ishida et al., 2007). Japanese maize inbred lines were at first screened for their tissue culture response, and Mi29 (Ikegaya et al., 1999) was adopted for its high in vitro regenerative ability. Immature embryos of Mi29 at 7-10 days after fertilization were infected with Agrobacterium containing either the standard binary vector or a super-efficient one and cultured on selection medium with 0.1 or 0.5 microM BS after a one-week co-cultivation period. Transgenic calli resistant to BS were transferred to regeneration medium, and regenerated shoots were further transferred to rooting medium. The overall transformation frequency was 5-30\% depending upon the stage and quality of the immature embryo. Transgenic BS-resistant maize grew to maturity and set seeds. $T_{1}$ progenies were obtained by crossing the transgenic maize with wild type. The inheritance of the transgene was confirmed by PCR analysis and BS application to their progenies. The progenies showed the segregation ratio (resistant: susceptible 1:1) expected for a single locus (Fig. 6). 


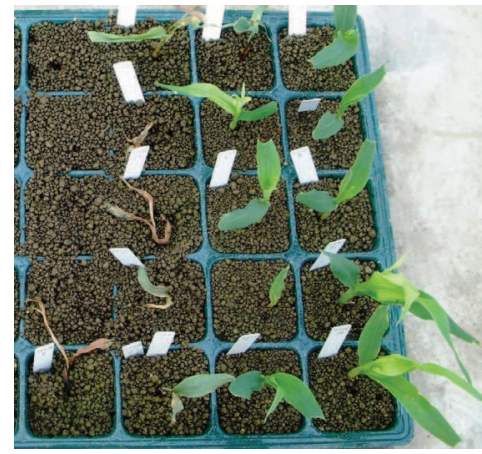

Fig. 6. Segregation of resistance to ALS-inhibiting herbicide containing BS in progenies of wild-type $x$ transgenic BS-resistant maize. 100-fold diluted commercial herbicide was sprayed one week after germination. The picture was taken after another week.

\section{The use of mutated $A L S$ genes as selective markers}

Selectable markers facilitate the selection of transgenic cells from non-transgenic cells in genetic transformation. Without them, the transgenic cells that integrate transgenes stably would be lost in non-transgenic cells, which would grow well in the absence of a selection agent. The most widely used selectable markers are antibiotic-resistant genes such as the $h p t$ gene and the nptII gene encoding neomycin phosphotransferase. HPT has a low likelihood of inducing toxicity and allergenicity (Zhuo et al., 2009; Lu et al., 2007), and NPTII was determined to be nontoxic for human or animal consumption (Nap et al., 1992). Herbicideresistant genes are also used as selectable markers. The bar gene encodes the enzyme phosphinothricin acetyltransferase (PAT) and confers resistance to phosphinothricin, glufosinate or bialaphos herbicides. PAT is specific and does not possess food toxins or allergens in human food and animal feed (Hérouet et al., 2005). The lack of toxicity or allergenicity of EPSPS has also been proved (Hammond et al., 2004).

However, some consumers are opposed to the use of these selectable markers because they are derived from bacterial or fungal DNA. Therefore, the use as selectable markers of mutated $A L S$ genes, derived from plant DNA, has recently increased. Mutated ALS genes derived from Arabidopsis have been reported to be useful as selectable markers in various plants, such as tobacco (Gabard et al., 1989), rice (Li et al., 1992), potato (Anderson et al., 2003), oilseed mustard (Brassica juncea) (Ray et al., 2004) and maize (Zhang et al. 2005). Mutated OsALS genes have been demonstrated to be useful as selectable markers in rice (Osakabe et al., 2005; Okuzaki et al., 2007). Using these mutated OsALS genes, transgenic plants have been produced in various plants such as rice (Osakabe et al., 2005; Okuzaki et al., 2007), soybeans (Tougou et al., 2009), tall fescue (in preparation) and wheat (Triticum aestivum L.) (Ogawa et al., 2008).

Some studies have suggested that homology-dependent gene silencing is associated with the presence of either multiple copies of homologous transgenes and promoters (Matzke \& Matzke, 1995) or a transgene and a homologous endogenous gene (Meyer, 1995). In general, constitutive promoters, such as the CaMV 35S promoter, rice actin 1 promoter and maize ubiquitin promoter, are used to drive selectable markers. In our transgenic tall fescue, multiple integrated transgenes were observed, and ALS activity was insufficient to confer herbicide resistance in susceptible plants (Sato et al., 2009). The CaMV 35 S promoter was used for two genes (OsALS (dm), hpt) in the same binary vector; therefore, the chances of gene silencing may have increased by overuse of the CaMV 35 S promoter. Okuzaki et al. 
(2007) reported that some transgenic rice calli with multiple copies of a mutated ALS gene driven by the maize ubiquitin promoter did not regenerate, whereas transgenic calli with only one or two transgenes did. On the other hand, no relationship between herbicide resistance and copy number was apparent in wheat transformation using the rice ALS promoter (Ogawa et al., 2008). It was assumed that the rice ALS promoter is not a strong one and is expressed in a tissue-specific manner (Osakabe et al., 2005). Strong expression in all tissues by constitutive promoters tends to cause deleterious effects, and the use of the endogenous ALS promoter would be preferable for more stable expression.

\section{Conclusion}

In this chapter, we introduced mutated ALS genes and their application to the production of herbicide-resistant crops and selection of transgenic cells. Our transgenic tall fescue and maize were confirmed to show ALS-inhibiting herbicide resistance in the greenhouse. So far, many transgenic herbicide-resistant crops have been developed. Though relatively new, their contribution to production-based agriculture has been significant. In future, we expect our herbicide-resistant crops to allow easier weed management.

Although herbicides are effective weed management tools, a cultivation system that depends on the application of a single type of herbicide with the same site of action would tend to increase the frequency of emergence of herbicide-resistant weed species or group of herbicides. Herbicide-resistant weeds evolve through random mutation events. In particular, there are more weed species that are resistant to ALS-inhibiting herbicides than to any other herbicides (Tranel \& Wright, 2002) because resistance to ALS-inhibiting herbicides is conferred by single or double mutations.

Recently, the adoption of stacked cultivars in which multiple transgenic traits were introduced has been produced in maize, soybeans and other crops. The use of a combination of several herbicides with other mechanisms and plants resistant to those herbicides is useful to inhibit and delay effectively the generation of herbicide-resistant weed species.

\section{References}

Andersson, M., Trifonova, A., Andersson, A. B., Johansson, M., Bülow, L. \& Hofvander, P. (2003). A novel selection system for potato transformation using a mutated AHAS gene. Plant Cell Rep. 22, 261-267.

Bernasconi, P., Woodworth, A. R., Rosen, B. A., Subramanian, M. V. \& Siehl, D. L. (1995). A naturally occuring point mutation confers broad range tolerance to herbicides that target acetolactate synthase. J. Biol. Chem. 270, 17381-17385.

Bettany, A. J. E., Dalton, S. J., Timms, E., Manderyck, B., Dhanoa M. S. \& Morris, P. (2003). Agrobacterium tumefaciens-mediated transformation of Festuca arundinacea (Schreb.) and Lolium multiflorum (Lam.). Plant Cell Rep. 21, 437-444.

Dong, S. \& Qu, R. (2005). High efficiency transformation of tall fescue with Agrobacterium tumefaciens. Plant Sci. 168, 1453-1458.

Fujimori, M. (2002). Breeding male sterile tall fescue. Japan Livestock Technol. 562, 15-18 (in Japanese).

Gabard, J. M., Charest P. J., Iyer V. N. \& Miki, B. L. (1989). Cross-resistance to short residual sulfonylurea herbicides in transgenic tobacco plants. Plant Physiol. 91, 574-580.

Gao, C., Long, D., Lenk, I. \& Nielsen, K. K. (2008). Comparative analysis of transgenic tall fescue (Festuca arundinacea Schreb.) plants obtained by Agrobacterium-mediated transformation and particle bombardment. Plant Cell Rep. 27, 1601-1609. 
Gerwick, B. C., Mireles, L. C. \& Eilers, R. J. (1993). Rapid diagnosis of ALS/AHAS-resistant weeds. Weed Technol. 7, 519-524.

Green, J. M. (2007). Review of glyphosate and ALS-inhibiting herbicide crop resistance and resistant weed management. Weed Technol. 21, 547-558.

Hammond, B., Dudek, R., Lemen, J. \& Nemeth, M. (2004). Results of a 13 week safety assurance study with rats fed grain from glyphosate tolerant corn. Feed Chem. Toxicol. 42, 1003-1014.

Hattori, J., Brown, D., Mourad, G., Labbé, H., Ouellet, T., Sunohara, G., Rutledge, R., King, J. \& Miki, B. (1995). An acetohydroxy acid synthase mutant reveals a single site involved in multiple herbicide resistance. Mol. Gen. Genet. 246, 419-425.

Hattori, J., Rutledge, R., Labbé, H., Brown, D., Sunohara, G. \& Miki, B. (1992). Multiple resistance to sulfonylureas and imidazolinones conferred by an acetohydroxyacid synthase gene with separate mutations for selective resistance. Mol. Gen. Genet. 232, 167-173.

Haughn, G. W. \& Somerville, C. R. (1990). A mutation causing imidazolinone resistance maps to the Csr1 locus of Arabidopsis thaliana. Plant Physiol. 92, 1081-1085.

Hérouet, C., Esdaile, D. J., Mallyon, B. A., Debruyne, E., Schulz A., Currier, T., Hendrickx, D., van der Kils, R. J. \& Rouan, D. (2005). Safety evaluation of the phosphinothricin acetyltransferase proteins encoded by the pat and bar sequences that confer tolerance to glufosinate-ammonium herbicide in transgenic plants. Reg. Toxic. Pharm. 41, 134-149.

Ikegaya, F., Koinuma, K., Ito, E., Inoue, Y., Nozaki, K., Fujita, K. \& Mochizuki, N. (1999). Development and characteristics of new inbred line 'Mi29' for silage maize. Bulletin of Kyusyu National Agricultural Experiment Station 35, 71-83 (in Japanese with English summary).

Ishida, Y., Hiei, Y. \& Komari, T. (2007). Agrobacterium-mediated transformation of maize. Nature protocols 2, 71614-1621.

Kawai, K., Kaku, K., Izawa, N., Fukuda, A., Tanaka, Y. \& Shimizu, T. (2007a). Functional analysis of transgenic rice plants expressing a novel mutated ALS gene of rice. J. Pestic. Sci. 32, 385-392.

Kawai, K., Kaku, K., Izawa, N., Shimizu, T., Fukuda, A. \& Tanaka, Y. (2007b). A novel mutant acetolactate synthase gene from rice cells, which confers resistance to ALSinhibiting herbicides. J. Pestic. Sci. 32, 89-98.

Lee, K. Y., Townsend, J., Tepperman, J., Black, M., Chui, C. F., Mazur, B., Dunsmuir, P. \& Bedbrook, J. (1988). The molecular basis sulfonylurea herbicide resistance in tobacco. EMBO J. 7, 1241-1248.

Lee, L. (1996). Turfgrass biotechnology. Plant Sci. 115, 1-8.

Lee, Y. T., Chang, A. K. \& Duggleby, R. G. (1999). Effect of mutagenesis at serine 653 of Arabidopsis thaliana acetohydroxyacid synthase on the sensitivity to imidazolinone and sulfonylurea herbicides. FEBS Lett. 452, 341-345.

Li, Z., Hayashimoto, A. \& Murai, N. (1992). A sulfonylurea herbicide resistance gene from Arabidopsis thaliana as a new selectable marker for production of fertile transgenic rice plants. Plant Physiol. 100, 662-668.

Lu, Y., Xu, W., Kang, A., Luo, Y., Guo, F., Yang, R., Zhang, J \& Huang, K. (2007). Prokaryotic expression and allergenicity assessment of hygromycin B phosphotransferase protein derived from genetically modified plants. J. Food Sci. 72, M228-M232.

Mallory-Smith, C. A., Thill, D. C. \& Dial, M. J. (1990). Identification of sulfonylurea herbicide-resistant prickly lettuce (Lactuca serriola). Weed Technol. 4, 163-168.

Matzke, M. A. \& Matzke A. J. M. (1995). How and why do plants inactivate homologous (trans)-genes? Plant Physiol. 107, 679-685. 
Meyer, P. (1995). Understanding and controlling transgene expression. Trends Biotechnol. 13, 332-337.

Nap, J. P.,Bijvoet, J. \& Willem, J. (1992). Biosafety of kanamycin-resistant transgenic plants. Transg. Res. 1, 239-249.

Ogawa, T., Kawahigashi, H., Toki, S. \& Handa, H. (2008). Efficient transformation of wheat by using a mutated rice acetolactate syhthase gene as a selectable marker. Plant Cell Rep. 27, 1325-1331.

Okuzaki, A., Shimizu, T., Kaku, K., Kawai, K. \& Toriyama, K. (2007). A novel mutated acetolactate synthase gene conferring specific resistance to pyrimidinyl carboxy herbicides in rice. Plant Mol. Biol. 64, 219-224.

Osakabe, K., Endo, M., Kawai, K., Nishizawa, Y., Ono, K., Abe, K., Ishikawa, Y., Nakamura, H., Ichikawa, H., Nishimura, S., Shimizu, T. \& Toki, S. (2005). The mutant form of acetolactate synthase genomic DNA from rice is an efficient selectable marker for genetic transformation. Mol. Breed. 16, 313-320.

Primiani, M., Cotterman, M. J. C. \& Saari, L. L. (1990). Resistance of kochia (kochia scoparia) to sulfonylurea and imidazolinone herbicides. Weed Technol. 4, 169-172.

Rajasekaran, K., Grula, J. W. \& Anderson, D. M. (1996). Selection and characterization of mutant cotton (Gossypium hirsutum L.) cell lines resistant to sulfonylurea and imidazolinone herbicides. Plant Sci. 119, 115-124.

Ray, K., Jagannath, A., Gangwani, S. A., Burma, P. K. \& Pental, D. (2004). Mutant acetolactate synthase gene is an efficient in vitro selectable marker for the genetic transformation of Brassica juncea (oilseed mustard). J. Plant Physiol. 161, 1079-1083.

Sato, H., Shimizu, T., Kawai, K., Kaku, K. \& Takamizo, T. (2009). Conferred resistance to an acetolactate synthase-inhibiting herbicide in transgenic tall fescue (Festuca arundinacea Schreb.). HortSci. 44, 1254-1257.

Schouten, H. J., Krens, F. A. \& Jacobsen, E. (2006). Do cisgenic plants warrant less stringent oversight? Nature Biotech. 24, 753.

Shimizu, T., Nakayama, I., Nagayama, K., Miyazawa, T. \& Nezu, Y. (2002). Acetolactate synthase inhibitors, in Böger, P., Wakabayashi, K. \& Hirai, K. of Editors (ed.), Herbicide classes in development, Springer-Verlag, Berlin, Germany, pp. 1-41.

Tan, S., Evans, R. R., Dahmer, M. L., Singh, B. K. \& Shaner, D. L. (2005). Imidazolinonetolerant crops: history, current status and future. Pest Manage. Sci. 61, 246-257.

Tarnel, P. J. \& Wright, T. R. (2002). Resistance of weeds to ALS-inhibiting herbicides: what have we learned? Weed Sci. 50, 700-712.

Tougou, M., Yamagishi, N., Furutani, N., Kaku, K., Shimizu, T., Takahata, Y., Sakai, J., Kanematsu, S. \& Hidaka, S. (2009). The application of the mutated acetolactate synthase gene from rice as the selectable marker gene in the production of transgenic soybeans. Plant Cell Rep. 28, 769-776.

Wang, Z. Y. \& Ge, Y. (2005). Agrobacterium-mediated high efficiency transformation of tall fescue (Festuca arundinacea). J. Plant Physiol. 162, 103-113.

Wright, T. R., Bascomb, N. F., Sturner, S. F. \& Penner, D. (1998). Biochemical mechanism and molecular basis for ALS-inhibiting herbicide resistance in sugarbeet (Beta vulgaris) somatic cell selections. Weed Sci. 46, 13-23.

Zhang, Y., Yin, X., Yang, A., Li, G. \& Zhang, J. (2005). Stability of inheritance of transgenes in maize (Zea mays L.) lines produced using different transformation methods. Euphytica. 144, 11-22.

Zhuo, Q., Piao, J. H., Tian, Y., Xu, J. \& Yang, X. G. (2009) Large-scale purification and acute toxicity of Hygromycin B phosphotransferase. Biomedical Environ. Sci. 22, 22-27. 


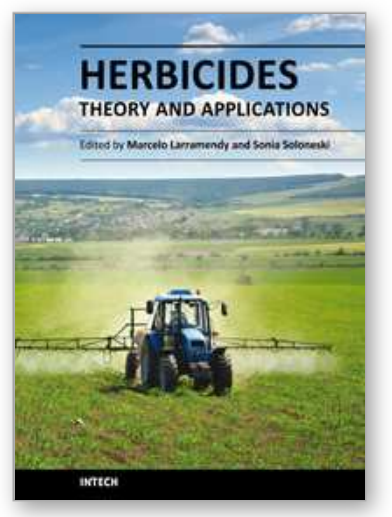

\author{
Herbicides, Theory and Applications \\ Edited by Prof. Marcelo Larramendy
}

ISBN 978-953-307-975-2

Hard cover, 610 pages

Publisher InTech

Published online 08, January, 2011

Published in print edition January, 2011

The content selected in Herbicides, Theory and Applications is intended to provide researchers, producers and consumers of herbicides an overview of the latest scientific achievements. Although we are dealing with many diverse and different topics, we have tried to compile this "raw material" into three major sections in search of clarity and order - Weed Control and Crop Management, Analytical Techniques of Herbicide Detection and Herbicide Toxicity and Further Applications. The editors hope that this book will continue to meet the expectations and needs of all interested in the methodology of use of herbicides, weed control as well as problems related to its use, abuse and misuse.

\title{
How to reference
}

In order to correctly reference this scholarly work, feel free to copy and paste the following:

Hiroko Sato, Tadashi Takamizo, Junko Horita, Kiyoshi Kawai, Koichiro Kaku and Tsutomu Shimizu (2011). Transgenic Tall Fescue and Maize with Resistance to ALS-Inhibiting Herbicides, Herbicides, Theory and Applications, Prof. Marcelo Larramendy (Ed.), ISBN: 978-953-307-975-2, InTech, Available from: http://www.intechopen.com/books/herbicides-theory-and-applications/transgenic-tall-fescue-and-maize-withresistance-to-als-inhibiting-herbicides

\section{INTECH}

open science | open minds

\author{
InTech Europe \\ University Campus STeP Ri \\ Slavka Krautzeka 83/A \\ 51000 Rijeka, Croatia \\ Phone: +385 (51) 770447 \\ Fax: +385 (51) 686166 \\ www.intechopen.com
}

\author{
InTech China \\ Unit 405, Office Block, Hotel Equatorial Shanghai \\ No.65, Yan An Road (West), Shanghai, 200040, China \\ 中国上海市延安西路65号上海国际贵都大饭店办公楼405单元 \\ Phone: +86-21-62489820 \\ Fax: $+86-21-62489821$
}


(C) 2011 The Author(s). Licensee IntechOpen. This chapter is distributed under the terms of the Creative Commons Attribution-NonCommercialShareAlike-3.0 License, which permits use, distribution and reproduction for non-commercial purposes, provided the original is properly cited and derivative works building on this content are distributed under the same license. 